\title{
Ultrasound Catheter Probe Detection of Appendiceal Mucocele
}

K. Akahoshi ${ }^{1}$, Y. Mizukami ${ }^{1}$, S. Yoshinaga ${ }^{1}$, M. Oya ${ }^{2}$, T. Nagaie ${ }^{3}$

${ }^{1}$ Department of Gastroenterology, Aso lizuka Hospital, lizuka, Japan

${ }^{2}$ Department of Pathology, Aso lizuka Hospital, Iizuka, Japan

${ }^{3}$ Department of Surgery,

Aso lizuka Hospital, lizuka, Japan

\section{Corresponding Author}

\section{K. Akahoshi, M.D.}

Department of Gastroenterology Aso lizuka Hospital

3-83 Yoshio

lizuka 820-8505

Japan

Fax: $\quad+81-948-298747$

E-mail: Kakahoshih1@aih-net.com

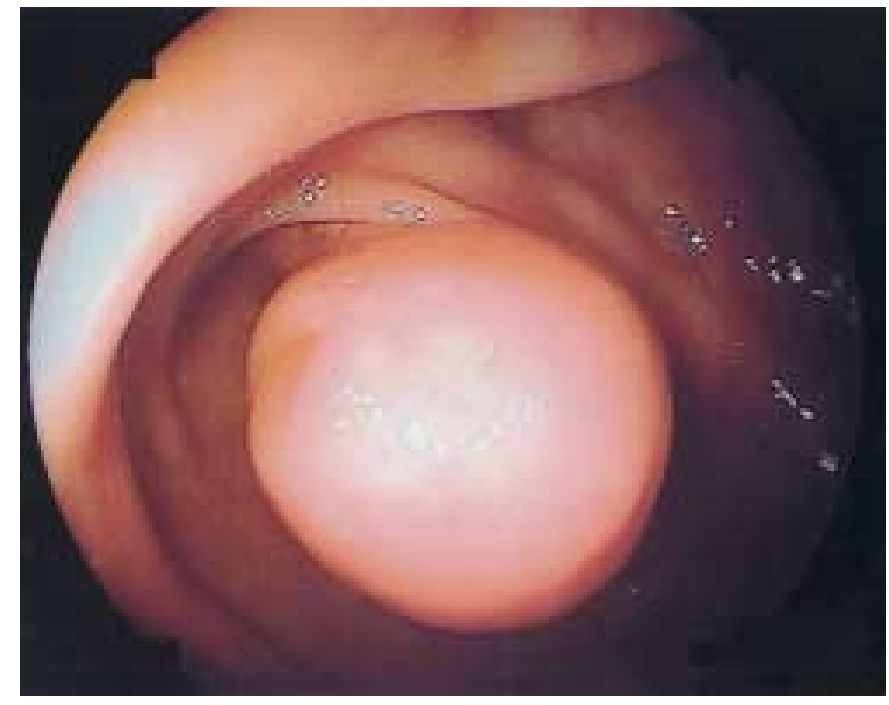

Figure 1 Colonoscopy on a 70-year-old man revealed a semipedunculated mass arising from the appendiceal orifice. The tumor was smooth and glossy and was covered with almost normal colonic mucosa; a depression in the top of the tumor was identified as the ostium of the vermiform appendix.
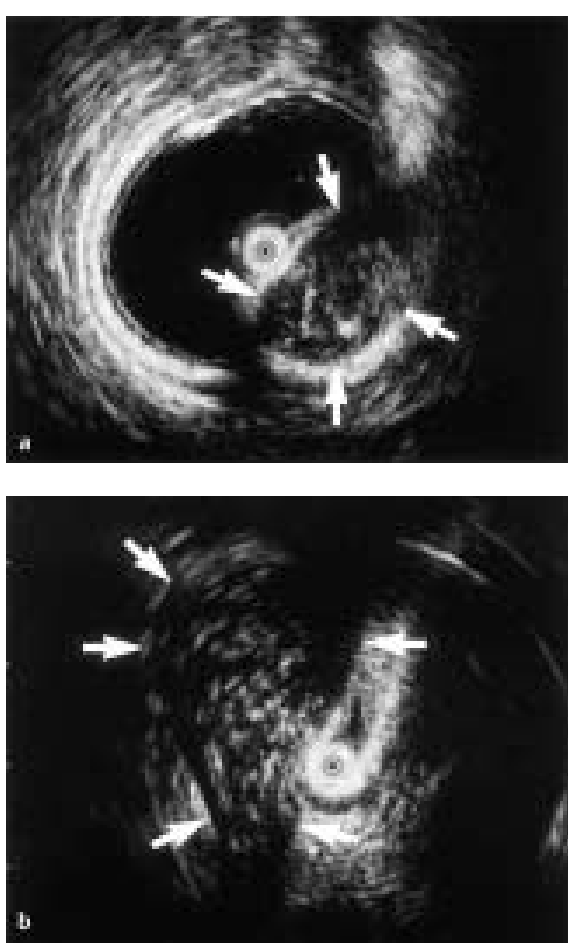

Figure 2 Subsequent endosonography using a 12-MHz ultrasound catheter probe (SP-701; Fujinon, Omiya, Japan) revealed a $30 \times 20-\mathrm{mm}$ monocystic mass (arrows) which was located in the layers from $\mathbf{a}$ the submucosa to $\mathbf{b}$ the extracecum. Scattered hyperechoic spots were observed in the cystic mass. Appendectomy was performed.

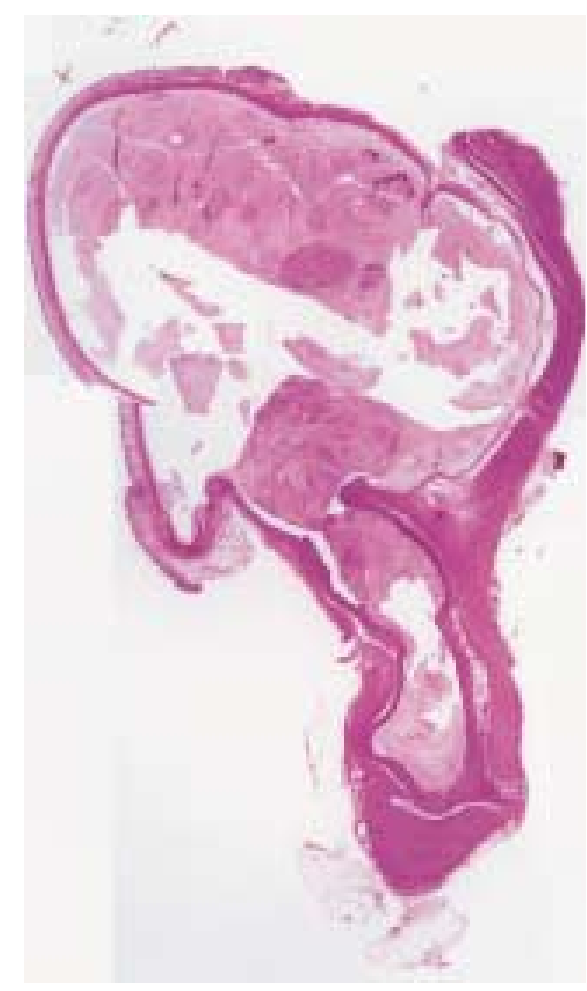

Figure 3 Incision of the cystic mass revealed that the lumen was filled with a gelatinous material. The histological diagnosis was benign appendiceal mucocele. 